\title{
Ensheathing Cells and Methylprednisolone Promote Axonal Regeneration and Functional Recovery in the Lesioned Adult Rat Spinal Cord
}

\author{
Holly H. Nash, ${ }^{1}$ Rosemary C. Borke, ${ }^{1,2}$ and Juanita J. Anders ${ }^{1,2}$ \\ ${ }^{1}$ Neuroscience Program and 2Department of Anatomy, Physiology, and Genetics, F. Edward Hébert School of Medicine, \\ Uniformed Services University of the Health Sciences, Bethesda, Maryland 20814-4799
}

Axons fail to regenerate after spinal cord injury (SCI) in adult mammals, leading to permanent loss of function. After $\mathrm{SCl}$, ensheathing cells (ECs) promote recovery in animal models, whereas methylprednisolone (MP) promotes neurological recovery in humans. In this study, the effectiveness of combining ECs and MP after SCl was investigated for the first time. After lesioning the corticospinal tract in adult rats, ECs were transplanted into the lesion, and MP was administered for $24 \mathrm{hr}$. At 6 weeks after injury, functional recovery was assessed by measuring successful performance of directed forepaw reaching (DFR), expressed as percentages. Axonal regeneration was analyzed by counting the number of corticospinal axons, anterogradely labeled with biotin dextran tetramethylrhodamine, caudal to the lesion. Lesioned control rats, receiving either no treatment or vehicle, had abortive axonal regrowth $(1 \mathrm{~mm})$ and poor DFR success (38 and 42\%, respectively). Compared with controls, MP-treated rats had significantly more axons $7 \mathrm{~mm}$ caudal to the lesion, and DFR performance was significantly improved (57\%). Rats that received ECs in combination with MP had significantly more axons than all other lesioned rats up to $13 \mathrm{~mm}$. Successful DFR performance was significantly higher in rats with EC transplants, both without (72\%) and with (78\%) MP, compared with other lesioned rats. These data confirm previous reports that ECs promote axonal regeneration and functional recovery after spinal cord lesions. In addition, this research provides evidence that, when used in combination, MP and ECs improve axonal regrowth up to $13 \mathrm{~mm}$ caudal to the lesion at 6 weeks after injury.

Key words: animal; axotomy; corticospinal tract; behavioral analysis; cultured cells; fluorescent tracers; forelimb function; glia; neuronal regeneration; olfactory bulb; recovery of function; spinal cord injury; Sprague Dawley rats
Unlike axons in the peripheral nervous system (PNS), which have the capacity to regrow (Fawcett and Keynes, 1990; Raivich and Kreutzberg, 1993), injured CNS axons fail to regenerate (Schwab and Bartholdi, 1996; Nicholls et al., 1999). The one exception is found in the olfactory system. Olfactory neurons have a life span of 4 weeks (Graziadei and Monti-Graziadei, 1978); when they die, new neurons originating from neuroepithelial precursors located in the olfactory epithelium (Graziadei and MontiGraziadei, 1978) successfully reinnervate the olfactory bulb and form functional synapses (Kosaka et al., 1998). Fascicles of olfactory axons are ensheathed throughout the PNS (Doucette, 1991) and into the CNS (Doucette, 1993) by a glial cell termed olfactory ensheathing cells (ECs) (Doucette, 1984).

Based on their unique ability to promote regeneration in the olfactory system, researchers have transplanted ECs after spinal cord injury (SCI) to determine whether ECs retained their ability

Received Dec. 26, 2001; revised May 23, 2002; accepted May 30, 2002.

This work was supported by the Brain Injury Association and the Defense Brain and Spinal Cord Injury Program. H.H.N. was a recipient of the Graduate Women in Science-Sigma Delta Epsilon Research Fellowship and a Defense Brain and Spinal Cord Injury Fellowship, as well as educational funding from the Defense Advanced Research Projects Agency. We are grateful to Drs. Barbara S. Bregman and Linda L. Porter for their wonderful suggestions and guidance, Anna Bergren, Christi Fredrikson, and Daniel Wilkinson for their expert technical assistance, and Sam Brake, Dwane Frye, and Chris Hite for their construction of the directed forepaw reaching apparatuses. We also thank Kimberly Byrnes and Tara Romanczyk for their endless assistance.

Correspondence should be addressed to Holly H. Nash, Department of Anatomy, Physiology, and Genetics, Uniformed Services University of the Health Sciences, 4301 Jones Bridge Road, Bethesda, MD 20814-4799. E-mail: hollyhnash@yahoo.com. Copyright (c) 2002 Society for Neuroscience $0270-6474 / 02 / 227111-10 \$ 15.00 / 0$ to promote regeneration. After injection of EC suspensions at the site of a dorsal rhizotomy in rats, regenerating axons regrew into the spinal cord gray matter (Ramon-Cueto and Nieto-Sampedro, 1994). ECs transplanted into spinal cord after electrolytic destruction of the corticospinal tract (CST) resulted in the growth of CST axons through the transplant into the host CST and restoration of directed forepaw reaching (DFR), a measure of function (Li et al., 1997). In a subsequent study using the same experimental model, regenerating CST axons were found in parallel bundles that crossed the lesioned area and reentered the spinal cord after transplantation of ECs into the injury site (Li et al., 1998). Using Schwann cell-filled guidance channels combined with injections of ECs, transected spinal cords were found to contain propriospinal axons that regenerated $2.5 \mathrm{~cm}$ (RamonCueto et al., 1998). Recently, ECs were shown to promote axonal regeneration and restore climbing abilities in rats after complete spinal cord transection (Ramon-Cueto et al., 2000). Therefore, ECs are recognized as a valuable tool in promoting spinal cord regeneration (Bartolomei and Greer, 2000; Franklin and Barnett, 2000; Raisman, 2001; Treloar et al., 2001).

A common treatment for SCI in human beings is administration of methylprednisolone (MP), a synthetic glucocorticoid steroid initially developed for its enhanced anti-inflammatory activity and lessened mineralocorticoid activity relative to cortisol, the prototypical glucocorticoid (Hall, 1992). The extreme lipophilicity of MP, a drawback to its intravenous use, has been overcome by the production of an MP-hemisuccinated ester (Solu-Medrol). When Solu-Medrol is injected into the body, the ester is liberated from the pro-drug, releasing the free steroid that is believed to 
cross the blood-brain barrier (Hall, 1992). Although glucocorticoids have been used in clinical treatment of spinal cord trauma since the 1960s, it was animal research investigating the neuroprotective pharmacology of MP at various dosing regimens after SCI (Braughler and Hall, 1982, 1983, 1984; McGinley et al., 1982; Hall et al., 1984; Braughler et al., 1987) that lead to the first (Bracken et al., 1984), second (Bracken et al., 1990), and third (Bracken et al., 1997) National Acute Spinal Cord Injury Study, to optimize parameters for neurological recovery after acute SCI in humans.

Although many therapies to promote regeneration after SCI have been investigated, at present, it does not appear that any single therapy will solve all of the problems associated with the lack of regeneration after SCI. Two therapies shown to promote repair after SCI when used alone are ECs and MP. Therefore, we examined the effects of combining MP administration with EC transplantation on regeneration of the CST after injury. Here we report that this combination of treatments promotes longdistance regrowth of CST axons and functional recovery after acute cervical SCI in the adult rat.

\section{MATERIALS AND METHODS}

\section{Subjects}

Eighty-one adult Sprague Dawley rats (300-400 gm; Taconic Farms, Germantown, NY) were used in this study. Twenty rats were use to harvest ECs for transplants, and 61 rats were randomly placed into control and experimental groups. Of those 61 rats, 17 were eliminated from the study either because they did not survive beyond $14 \mathrm{~d}$ after surgery $(n=15)$ or they failed to train in response to a food reward before surgery $(n=2)$.

\section{Surgeries}

\section{Cultures}

ECs were harvested and purified following a previously described technique (Nash et al., 2001). Briefly, the rats were anesthetized and decapitated, and the nasal and frontal bones were removed. Olfactory nerve rootlets and olfactory bulbs were detached. The rootlets and outer two layers of the olfactory bulb were dissected, retained, triturated, and trypsinized. After the cells were centrif uged, media was added to yield a suspension containing $8.5 \times 10^{5}$ cells $/ \mathrm{ml}$. The cell suspension was seeded into an uncoated flask and incubated $\left(48 \mathrm{hr}, 37^{\circ} \mathrm{C}\right.$ and $\left.5 \% \mathrm{CO}_{2}\right)$ for purification. During this $48 \mathrm{hr}$ period, all other cell types in the cell suspension attached to the uncoated plastic flask, whereas the ECs remained in the supernatant. Using this, our previously described purification process (Nash et al., 2001), the ECs had been found to be $\sim 93 \%$ pure. Right after purification, the ECs were centrif uged and labeled with Cell Tracker green $(50 \mu \mathrm{M}$; Molecular Probes, Eugene, OR) for immediate transplantation.

\section{Surgical procedures}

Rats were randomly assigned to control or experimental groups. The three control groups were as follows: sham $(n=5)$, lesion $(n=5)$, and vehicle $(n=5)$. The three experimental groups were as follows: MP $(n=$ $10)$, EC $(n=9)$, and $\mathrm{MP} / \mathrm{EC}(n=10)$.

After anesthesia with isoflurane $(5 \%$; Abbott Laboratories, North Chicago, IL) and application of ophthalmic ointment (E. Fougera \& Co., Melville, NY), the rats were placed on an operating board in such a way as to bend the cervical spinal cord for maximum exposure. A laminectomy was performed exposing the dorsum of the spinal cord between $\mathrm{C} 2$ and $\mathrm{C} 4$. The dorsal columns were identified bilaterally, and, in all rats except for those in the sham group, a suture needle was passed through the spinal cord, isolating the dorsal funiculus. The suture thread was gently lifted, and a pair of iridectomy scissors was used to bilaterally transect the dorsal funiculus, thereby transecting the dorsal CST. Visualization of the dorsal horns and the central gray commissure confirmed accuracy of the lesion borders. ECs prelabeled with Cell Tracker green were injected (10 $\mu$ l Hamilton syringe) into the cut surfaces of the CST (two injections in the rostral surface and two in the caudal surface). The injections were made just below the cut surface of the spinal cord, and each injection was $\sim 500 \mu \mathrm{m}$ lateral to the posterior median septum and $\sim 500 \mu \mathrm{m}$ dorsal to the central gray matter. Each injection site received $0.5 \mu \mathrm{l}$ of a suspension containing 50,000 ECs in DMEM (Biofluids, Rockville, MD), and injections were administered consecutively over $\sim 2$ min. Rats receiving the vehicle for ECs were injected with an equal volume of DMEM into the CST. A pledget of biodegradable Gelfoam soaked in Fluorogold (3\% in $0.9 \%$ saline; Molecular Probes) was placed in the lesion site (see Tracers below). The overlying muscles and skin were sutured, and the rats were placed on a heating pad to maintain body temperature. Each rat received a single dose of buprenorphine $(0.1$ $\mathrm{mg} / \mathrm{kg}$; Reckitt \& Colman Pharmaceuticals, Richmond, VA) immediately after surgery to alleviate pain. One hour after the spinal cord was lesioned, a bolus injection of MP sodium succinate (Solu-Medrol, 30 $\mathrm{mg} / \mathrm{kg}$; Pharmacia Upjohn, Kalamazoo, MI) in $0.9 \%$ saline was administered via a tail vein. This injection was followed by four subsequent administrations of MP into a tail vein $(30 \mathrm{mg} / \mathrm{kg})$ at $6 \mathrm{hr}$ intervals. Rats receiving vehicle for MP underwent the same treatment regimen but were injected with an equal volume of $0.09 \%$ saline in a tail vein. For all lesioned rats, their bladders were manually expressed immediately after surgery and three times per day until spontaneous urination returned.

\section{Tracers}

During surgery (see Surgical procedures), a fluorescent retrograde tracer, Fluorogold, was administered to identify the neurons whose axons were transected, confirming the lesion. Seven weeks after injury, rats were prepared for injection of biotin dextran tetramethylrhodamine (BDT; Molecular Probes). This fluorescent anterograde tracer, injected into the primary motor cortex, was used to label CST axons caudal to the lesion site in the spinal cord. After anesthesia with isoflurane (5\%), rats were placed in a stereotaxic instrument, and a total of six stereotaxically determined holes $(0.9 \mathrm{~mm}$ diameter) were drilled in the skull over the primary motor cortices associated with the forelimbs. The anteroposterior (AP) and mediolateral (ML) coordinates for these injections, from bregma, were as follows: $+0.5 \mathrm{AP}$ and $\pm 3.5 \mathrm{ML} ;+1.5 \mathrm{~A} / \mathrm{P}$ and $\pm 2.5 \mathrm{ML}$; and $+2.5 \mathrm{AP}$ and $\pm 1.5 \mathrm{ML}$. All injections were delivered at a depth of 2.5 $\mathrm{mm}$ from the surface of the skull. A $10 \mu \mathrm{l}$ Hamilton syringe was used to inject BDT bilaterally into layer V of the cortex. Three injections into each cortical hemisphere were used to administer a total of $1.2 \mu$ l of the anterograde tracer. Bone wax (Ethicon, Somerville, NJ) was used to seal the holes in the skull, the scalp was sutured, and a single dose of buprenorphine $(0.1 \mathrm{mg} / \mathrm{kg})$ was administered immediately after surgery to alleviate pain. Rats were killed $3 \mathrm{~d}$ after tracer injections.

\section{Functional testing \\ Apparatus}

A modified version of an apparatus (Castro, 1972) designed to test DFR was used to measure grasping ability (Fig. $1 A, B$ ). The apparatus was a box with two compartments separated by a Plexiglas divider. The two compartments comprised a main compartment $(30.5 \times 6.25 \times 5$ inches $)$ for the rat and a minor compartment $(30.5 \times 3.5 \times 3$ inches $)$ for the food reward, which was subdivided into 14 adjacent slots of equal size $(2 \times$ $1.25 \times 3$ inches). The floor of the minor compartment was made of a movable shelf. The shelf was usually pulled back to produce a 0.75 inch opening in the floor between the compartments but could be pushed in (see Testing procedures) to produce a continuous floor between the two compartments. All presurgical and postsurgical testing was performed with the three-quarter inch opening in the floor. The Plexiglas divider $(30.75 \times 0.25 \times 5$ inches $)$ separating the rat compartment from the food compartment had 14 semicircular holes drilled into the bottom, each of which was 0.50 inches in diameter

A single $190 \mathrm{mg}$ food pellet (Bio-Serv, Frenchtown, NJ) was placed into each of the 14 slots in the minor compartment. The rats were required to extend a forelimb through the holes in the Plexiglas divider to grasp a food pellet. The rats could use either forelimb to retrieve the food pellet, but the holes in the Plexiglas divider were only large enough to admit one limb at a time. The opening in the floor ensured that the rats grasped and lifted the food pellet to retrieve it. If a rat attempted to scoop or rake a pellet out of the slot without grasping and lifting it, the pellet would fall irretrievably through the opening in the floor.

\section{Testing procedures}

Before surgery. Rats were food restricted, receiving $\sim 3 \mathrm{gm}$ food $/ 100 \mathrm{gm}$ body weight per day, before and throughout training and testing. Weight was monitored to ensure that rats were reduced to no less than $80 \%$ of 


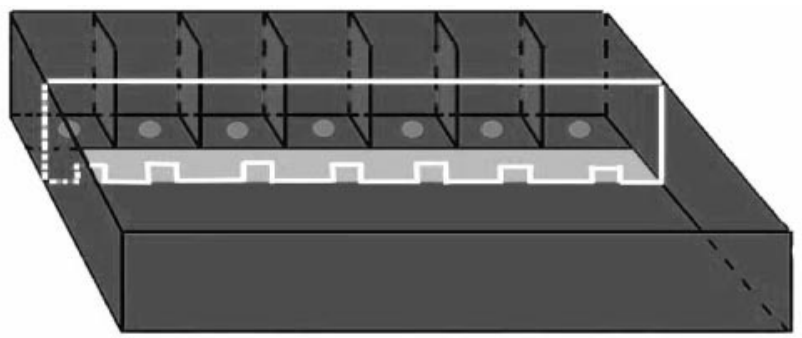

A

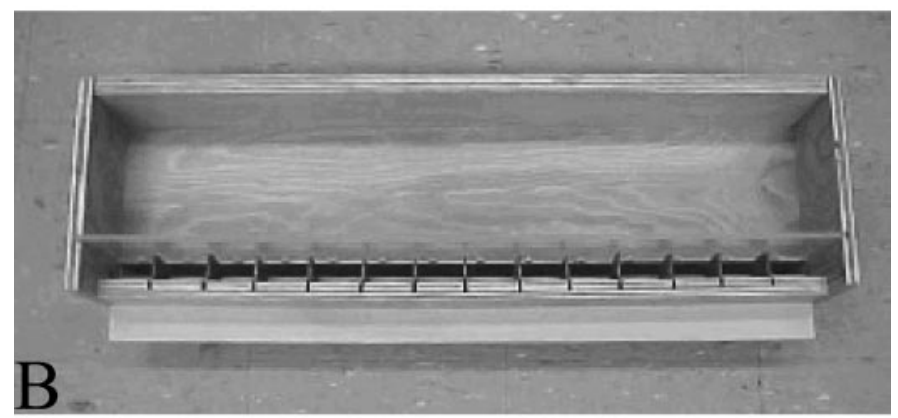

Pre-Surgery DFR Success

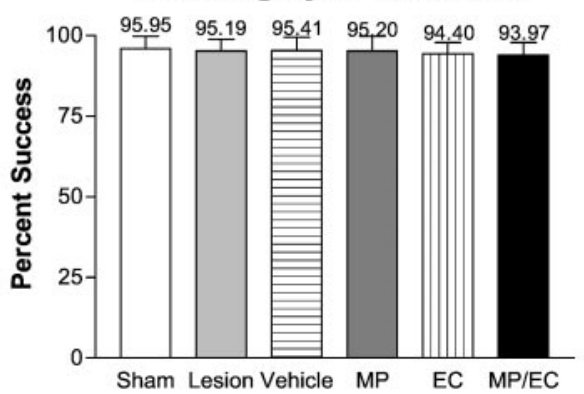

Post-Surgery DFR Success

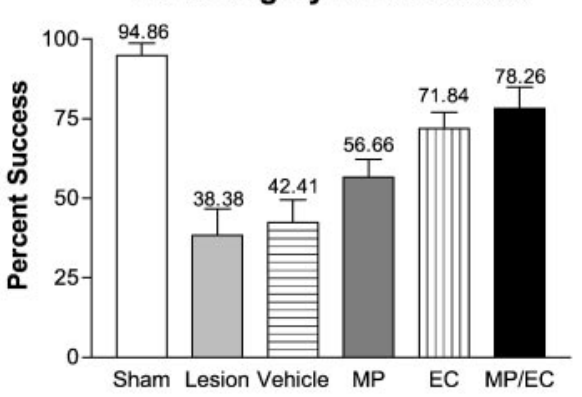

Figure 1. DFR apparatuses and functional performance. $A$, A schematic of the DFR apparatus, viewed from the front, with the opening in the floor at 0.75 inches. The circles represent food pellets used as a reward. $B$, The DFR apparatus, viewed from above, with the opening in the floor at 0.75 inches, as was used for all testing procedures. $C$, Graph showing the successful performance of the DFR task (expressed as percentages of total attempts) when tested before surgery. As was required for inclusion in the study, the rats in all of the groups performed the DFR task successfully at least $90 \%$ of the trials. D, Graph showing DFR success for each group after surgery (expressed as percentages of total attempts). The sham group $(94.86 \pm 0.86 \%)$ performed significantly better than all of the other groups. There was no significant difference in DFR success between the lesion $(38.38 \pm 8.31 \%)$ and vehicle $(42.41 \pm 7.10 \%)$ groups, although both performed significantly worse than the MP group $(56.66 \pm 5.63 \%)$. Groups receiving ECs, both alone $(71.84 \pm 5.20 \%)$ and in combination with MP $(78.26 \pm 0668 \%)$, performed the DFR task significantly better than all other lesioned animals; however, these two groups were not significantly different from each other. their original body weight at any time. All rats were given shaping periods for $2-3 \mathrm{~d}$ in the box to allow them to learn the task while they became familiar with the testing situation. During these shaping periods, the Plexiglas divider was initially raised 1 inch above the floor, then lowered to 0.25 inches, and then positioned flush against the floor; all rats were trained and tested at this most stringent level. It has been demonstrated that rats exhibit a paw preference that can be disrupted after unilateral lesioning of the neurons or axons corresponding to the preferred limb (Castro, 1977; Kartje-Tillotson and Castro, 1980). In our study, however, a bilateral lesion was created that disrupted grasping in both paws; therefore, data on paw preference was not collected. Animals were trained twice per day for $5 \mathrm{~d}$ and then tested twice per day for $5 \mathrm{~d}$, and presurgical DFR data were collected. During the testing period, rats were given $5 \mathrm{~min}$ to complete the task and were allowed to make as many attempts as they wanted during this time period. Rats were required to return to at least $95 \%$ of their original weight to ensure that they were healthy before undergoing surgery.

After surgery. Rats were trained twice per week during weeks 2-5 after surgery. Some rats were profoundly impaired when they attempted to perform the grasping portion of the DFR task in the early postsurgical period and were therefore completely unable to retrieve the food reward. For those rats, the opening in the floor of the apparatus was closed to allow the food to be raked into the main compartment, ensuring that the reaching portion of the DFR task did not extinguish. The severity of the grasping impairment decreased as the postsurgical period increased, and the opening in the floor was gradually reestablished. By the end of the postsurgical recovery period, all rats were able to successfully perform the DFR task, to some degree, with the 0.75 inch opening in the floor of the apparatus. During the sixth week after surgery, rats were tested twice per day for $5 \mathrm{~d}$, and postsurgical DFR data were collected by a blinded investigator. Just as during the presurgery testing period, the rats were allowed 5 min to complete the task during the postsurgery testing period and were allowed to make as many attempts as they wanted during this time period.

The data were collected in terms of total number of attempts and percentage of successful attempts. An attempt was scored only when a rat reached into a slot and displaced the pellet or dropped it through the gap in the floor. A successful attempt was scored when a rat grasped a pellet, lifted it over the gap in the floor, and pulled it through the Plexiglas divider so the pellet was in the main portion of the testing apparatus. This conservative method of counting was used to reduce arbitrariness by the investigator and was important for interpretation of the data. Data were analyzed using the statistical software program Prism. A one-way ANOVA was performed, with an $\alpha$ level of 0.05 , followed by a Bonferroni's multiple comparison test. Data are presented as mean \pm SEM percentages.

\section{Histology}

Seven weeks and $3 \mathrm{~d}$ after lesioning, rats were anesthetized with chloral hydrate $(10 \mathrm{ml} / \mathrm{kg}$; Sigma, St. Louis, MO) and perfused transcardially with $300 \mathrm{ml}$ of PBS, $\mathrm{pH} 7.4$, followed by $300 \mathrm{ml}$ of $4 \%$ paraformaldehyde in $0.1 \mathrm{M}$ phosphate buffer. After the animals were killed, all brains and spinal cords were removed and soaked overnight in $30 \%$ sucrose in a 0.1 M phosphate buffer solution. The brains were cut coronally and the spinal cords were cut horizontally at a thickness of $20 \mu \mathrm{m}$ with a freezing

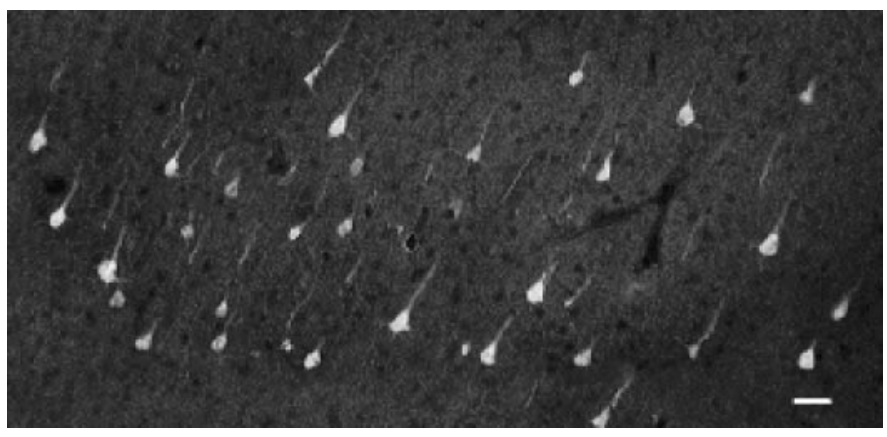

Figure 2. Fluorogold-labeled CST neurons. These neurons, filled with the retrograde tracer Fluorogold, are the origin of the corticospinal axons that were severed in the spinal cord at $\mathrm{C} 3$. Fluorogold can be seen filling the soma, axons, and dendrites of these neurons. Scale bar, $50 \mu \mathrm{m}$. 


\section{$1 \mathrm{~mm}$}
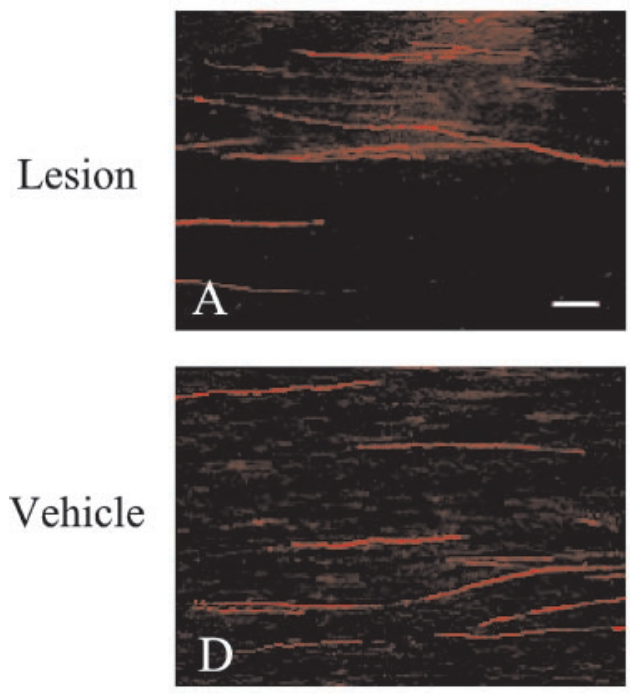

MP

EC
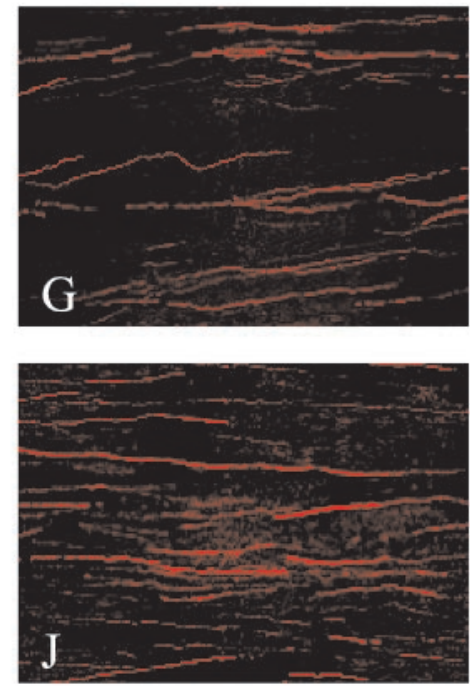

MP/EC

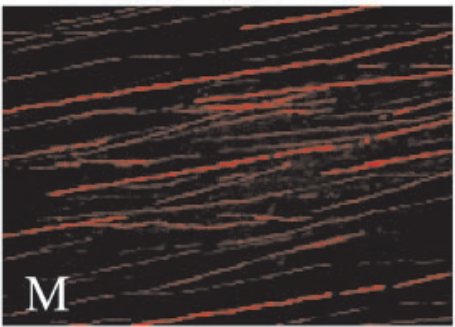

Sham

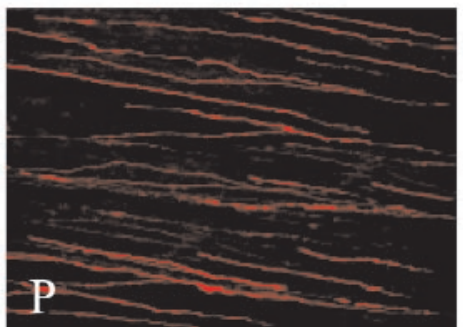

$10 \mathrm{~mm}$
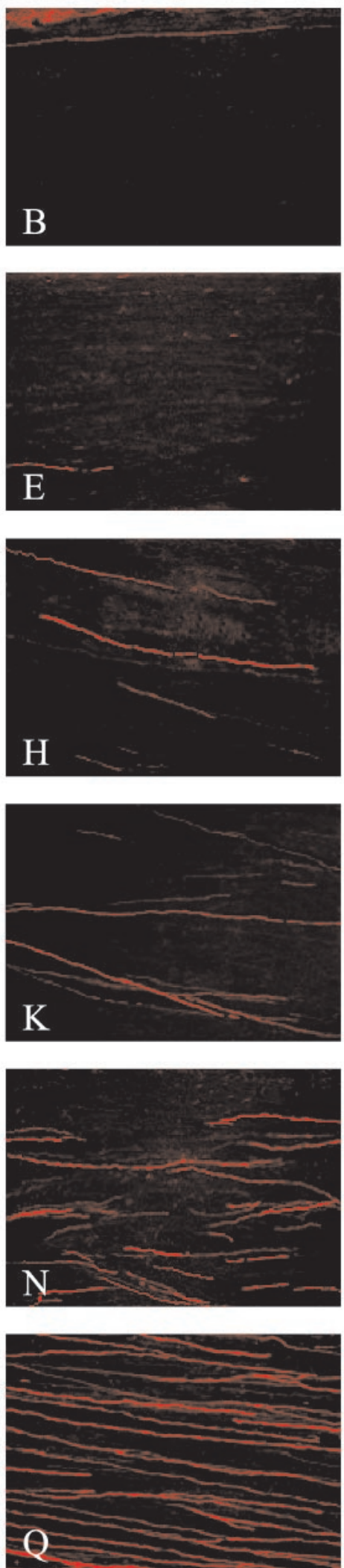

$19 \mathrm{~mm}$
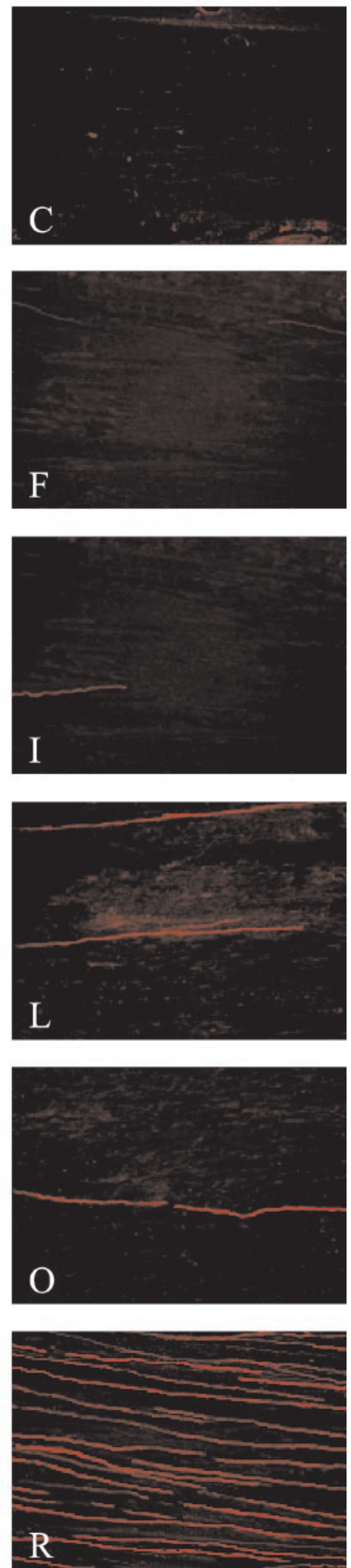

Figure 3. Data from 1, 10, and $19 \mathrm{~mm}$ caudal to the lesion. Representative photomicrographs of axons from the lesion, vehicle, MP, EC, MP/EC, and sham groups at each of these three distances caudal to the lesion. Axons are red because they are labeled with BDT. At $1 \mathrm{~mm}$ caudal to the lesion, there is no significant difference between mean number of axons of the lesion $(A ; 9.58 \pm 5.53)$ and vehicle $(D ; 10.95 \pm 3.25)$ groups, but there are significantly more axons in the MP group $(G ; 32.01 \pm 3.41)$. The EC group $(J ; 43.57 \pm 3.05)$ has significantly more axons than the MP group, and the MP/EC group $(M ; 55.99 \pm 2.96)$ has significantly more axons than all other lesioned groups. At this distance only, there is no significant (Figure legend continues.) 
microtome and mounted on ProbeOn (Fisher Scientific, Pittsburgh, PA) coated slides. Brain and spinal cord sections were examined using a Nikon (Tokyo, Japan) Labophot fluorescent microscope, and images were captured using a Sony (Tokyo, Japan) DKC 5000 Catseye digital still camera. The forelimb representation of the primary motor cortex was identified based on the stereotaxic BDT injection sites. Detection of Fluorogold-labeled neurons in layer $\mathrm{V}$ of the forelimb representation of the primary motor cortex confirmed lesioning of the CST, because Fluorogold is taken up by cut axons but not intact axons.

\section{Axonal counts}

The spinal cord caudal to the lesion was examined, and the BDT-labeled axons occupying the region of the spinal cord normally occupied by the dorsal CST were counted. After consulting with a biomedical statistician, it was determined that, with a $95 \%$ confidence level and an SD of 10 axons, a sampling fraction of 1:4 sections would result in a precision of $X \pm 5.4$ axons. A random starting section to begin counts was determined by randomly selecting a number between 1 and 4 . For each section, the number of BDT-labeled axons was counted at $3 \mathrm{~mm}$ intervals caudal to the lesion, beginning $1 \mathrm{~mm}$ distal to the injury (i.e., $1 \mathrm{~mm}, 4 \mathrm{~mm}, 7 \mathrm{~mm}$, etc.) and ending $19 \mathrm{~mm}$ caudal to the lesion site. Innervation of the rat forepaw extends to $\mathrm{T} 1$, a distance of $15.1 \mathrm{~mm}$ from the lesion at $\mathrm{C} 3$. Therefore, analysis of the axons out to $19 \mathrm{~mm}$ caudal to the lesion ensured that the entire distance representing the forepaw was examined. At each interval, the total number of BDT-labeled axons (left and right CST combined) along a $500 \mu \mathrm{m}$ length (length of microscope field) was counted. In each field counted, the focal plane was adjusted up and down to ensure that a single continuous axon was not double counted if it traversed out of the focal plane and reemerged farther down in the same field. After the data were compiled, they were analyzed using the statistical software program Prism. A one-way ANOVA was performed, with an $\alpha$ level of 0.05 , followed by a Bonferroni's multiple comparison test for the data from all of the groups at each interval counted. Data are presented as mean \pm SEM number of axons.

\section{RESULTS}

\section{Immediate postoperative observations}

During the week after surgery, all animals were observed for lack of bladder control, wound opening, and signs of infection but were not systematically analyzed for neurological deficits. In some animals, a slight paresis and/or ataxia was noted, but these symptoms resolved within 2 weeks of surgery.

\section{Functional recovery}

Rats were tested before surgery to establish a DFR presurgery baseline. This presurgical baseline ensured that all rats were functionally capable of performing the DFR task before lesioning. To prevent differences in presurgical ability from influencing the postsurgical scores, all rats were required to perform the DFR task at a success rate of at least $90 \%$. As noted at the beginning of Materials and Methods, two rats did not perform at this level and were therefore eliminated from the study. All other rats met the criterion necessary for inclusion in the study. The presurgery DFR scores (Fig. 1C) for each group were as follows: sham, $95.95 \pm 3.91$; lesion, $95.19 \pm 3.72$; vehicle, $95.41 \pm 4.11$; MP, $95.20 \pm 4.59 ; \mathrm{EC}, 94.40 \pm 3.47$; and $\mathrm{MP} / \mathrm{EC}, 93.97 \pm 3.89$.

During the sixth week after injury, rats were tested to assess their ability to perform the DFR task (Fig. 1D). Using this functional test, the sham animals performed the DFR task as well postsurgically $(94.86 \pm 3.86 \%)$ as they did presurgically. This finding demonstrated that only the lesion, and no other portion of the surgical procedure, inhibited the rats' abilities to perform the DFR task. When compared with the sham group, a significant functional deficit was noted in all rats that were lesioned, regardless of their treatment group. However, this functional deficit in performing the DFR task was not the same across all of the experimental groups.

The lesion and vehicle groups were the most impaired of all of the groups after surgery. The lesion and vehicle groups were able to perform the DFR task with a success rate of only $38.38 \pm 8.31$ and $42.41 \pm 7.10 \%$, respectfully; there was no significant difference between these two groups. The MP group, with a success rate of $56.66 \pm 5.63 \%$, performed significantly better than the lesion and vehicle groups. The EC group performed the DFR task significantly better than the lesion, vehicle, and MP groups, with a success rate of $71.84 \pm 5.20 \%$. Like the EC group, the $\mathrm{MP} / \mathrm{EC}$ group, with a success rate of $78.26 \pm 6.68 \%$, performed the DFR task significantly better than the lesion, vehicle, and MP groups. Although the group that received the combination treatment of ECs and MP performed the DFR task with a higher success rate $(78.26 \%)$ than the group that received ECs alone $(71.84 \%)$, this difference was not statistically significant.

\section{Histology and axonal counts}

\section{Fluorogold-labeled neurons}

The primary motor cortex was examined in all rats used in this study. All of the brains contained Fluorogold-labeled neurons in layer $\mathrm{V}$ of the primary motor cortex, confirming that the dorsal CST axons were transected during the lesioning procedure (Fig. 2). Because all CST axons located in the dorsal funiculus were transected during surgery and not just those in the forelimb representation, Fluorogold-labeled neurons were found throughout the primary motor cortex in layer $\mathrm{V}$. Unlabeled pyramidal neurons were also found scattered throughout the primary motor cortex in layer V. It is believed that these neurons correspond to uncrossed CST axons located in the ventral funiculus of the spinal cord. The only exception to this labeling pattern was in the brains of the rats that were in the sham group, whose brains had no Fluorogold label.

\section{Biotin dextran tetramethylrhodamine-labeled axons}

All of the groups showed some CST axonal growth caudal to the lesion, although regrowth was not necessarily found in all of the animals in every group. There were three rats (two lesion and one vehicle) that did not have any BDT-labeled CST axons caudal to the lesion site. To ensure that the lack of labeled CST axons did not result from a problem with the BDT or the labeling technique, the spinal cords of these three rats were examined rostral to the lesion. All three were found to have BDT-labeled CST axons proximal to the injury site.

In all groups, CST axons were found to course in the white matter of the dorsal funiculus and, on occasion, were seen to

\section{$\leftarrow$}

(Figure legend continued.) difference between the MP/EC and sham $(P ; 59.02 \pm 4.01)$ groups. At $10 \mathrm{~mm}$ distal to the lesion, there is no significant difference between the lesion $(B ; 0.66 \pm 0.59)$, vehicle $(E ; 0.73 \pm 0.73)$, and MP $(H ; 5.85 \pm 0.91)$ groups. All three of these groups have significantly fewer axons than the EC group $(K ; 12.35 \pm 2.57)$, and the EC group has significantly fewer axons than the MP/EC group $(N ; 22.48 \pm 6.00)$. There are significantly more axons in the sham group than in all the other groups at this distance $(Q ; 53.26 \pm 3.88)$. At $19 \mathrm{~mm}$, the lesion $(C ; 0.02 \pm 0.02)$, vehicle $(F ; 0.04 \pm 0.04)$, and $\mathrm{MP}(I ; 0.18 \pm 0.03)$ groups are still not statistically different. The EC $(L ; 2.18 \pm 0.16)$ and $\mathrm{MP} / \mathrm{EC}(O ; 2.23 \pm 0.20)$ groups have significantly more axons than all other lesioned groups, but there is no significant difference between these groups. The sham group has significantly more axons than all other groups at this distance $(R ; 52.19 \pm 2.96)$. Scale bar, $50 \mu \mathrm{m}$. 
Figure 4. Graphical and tabular presentation of the axonal data. Graphs of the mean number of axons for the lesion, vehicle, MP, EC, and MP/EC groups at $1 \mathrm{~mm}(A), 10 \mathrm{~mm}(B)$, and 19 $\mathrm{mm}(C)$ caudal to the lesion. Because the axon means are so high at all distances relative to the axon means for the other groups, the data for the sham group are only presented graphically at $1 \mathrm{~mm}$ caudal to the lesion $(A)$. The table $(D)$ is included to provide the complete set of data for the axon counts at the seven distances $(1,4,7,10,13,16$, and $19 \mathrm{~mm}$ ) caudal to the lesion for the three control and three experimental groups used in this study. Data are presented as mean \pm SEM number of axons.

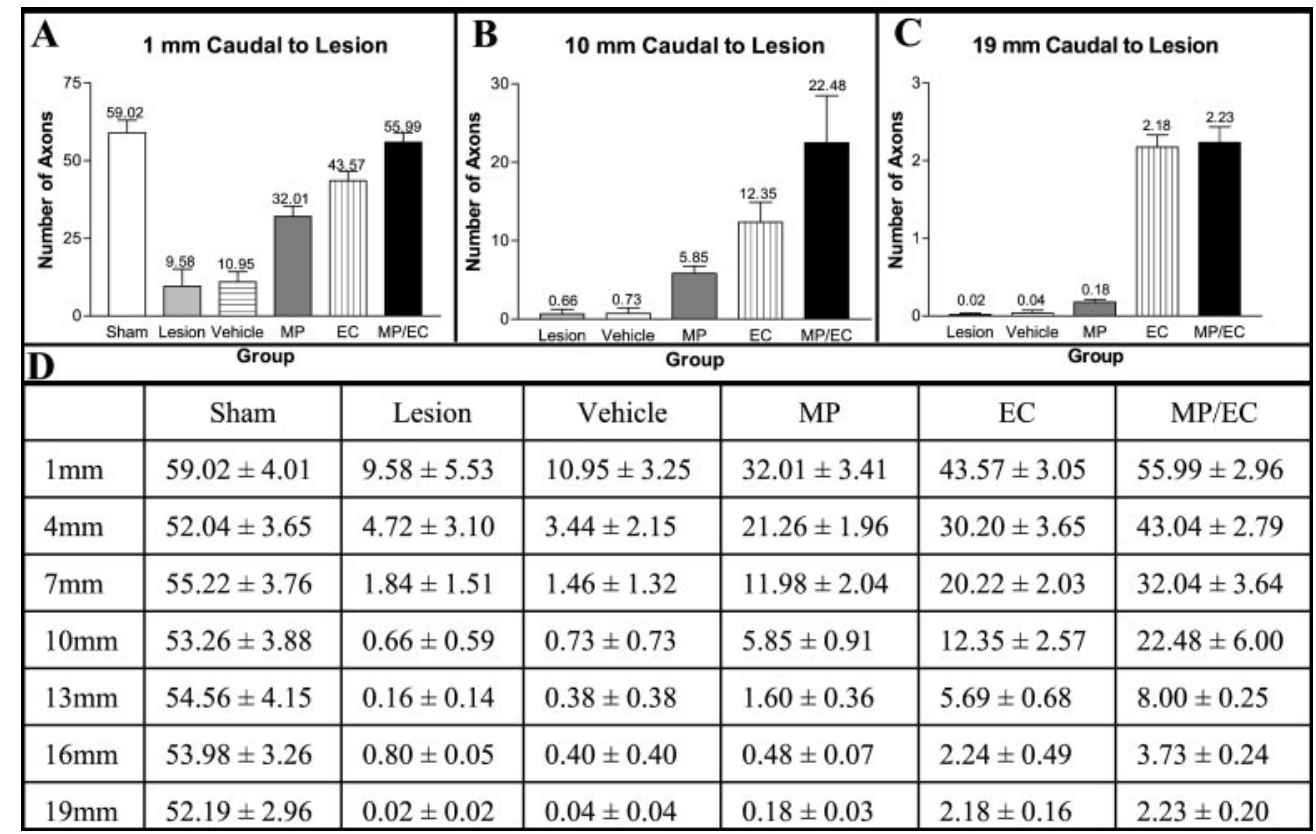

enter the gray matter. When these CST axons did migrate into the gray matter, they coursed along the border between the gray and white matter. In those rats that received EC transplants, ECs were found to migrate throughout the spinal cord white matter; however, they were rarely found in the spinal cord gray matter. Although the ECs were not found to specifically align along the length of the axons, the ECs were found in all areas in which regrowing axons were seen. The tissue was analyzed up to $19 \mathrm{~mm}$ caudal to the lesion, and ECs were visible at this distance and densities that qualitatively appeared to be similar to all distances analyzed at $4 \mathrm{~mm}$ caudal to the lesion and beyond. However, ECs did appear to be most dense at $1 \mathrm{~mm}$ caudal to the lesion.

The number of BDT-labeled axons present was examined for all control and experimental groups at 1, 4, 7, 10, 13, 16, and 19 $\mathrm{mm}$ caudal to the lesion site. A representative photomicrograph from each group (Fig. 3) and a graph comparing the means from the groups (Fig. $4 A-C$ ) are presented for 1,10 , and $19 \mathrm{~mm}$. Presented in Figure $4 D$ is the mean number of labeled axons for each group at all of the distances examined. Differences between the means of groups were difficult to visualize on most of the graphs when the sham group data were included because the means for the sham group were much larger than the means of all the other groups, except at $1 \mathrm{~mm}$. Therefore, the data for the sham group are only represented graphically in Figure $4 A$, which presents the data for the groups at $1 \mathrm{~mm}$ caudal to the lesion. Throughout all of the examined intervals, the mean number of axons were highest in the sham group (Fig. 4D), and, at each distance examined, the mean number of labeled axons in the sham group was significantly higher than in all other groups, with one exception, which is noted below.

Supporting the functional data reported above, there was no significant difference between the means of the lesion and vehicle groups at any distance examined (Fig. 4). In these two groups, axons were found only a short distance caudal to the injury (Fig. $4 A$ ), and, by $10 \mathrm{~mm}$ distal to the lesion (Fig. $4 B$ ) to the farthest distance examined (Fig. $4 C$ ), all of the tissue was virtually devoid of axons in both the lesion (Figs. $3 A-C, 4 D$ ) and vehicle (Figs. $3 D-F, 4 D)$ groups.
In the MP group, axons could be found through $7 \mathrm{~mm}$; however, at $10 \mathrm{~mm}$ and beyond, the MP had very few labeled axons (Figs. 3G-I, 4D). When analyzed statistically, the MP group had significantly more axons than the lesion and vehicle groups at 1, 4, and $7 \mathrm{~mm}$ (Fig. 4A,D). However, at 10, 13, 16, and $19 \mathrm{~mm}$, no significant differences were found among the means of these three groups (Fig. $4 B-D$ ).

In examining the photomicrographs of the tissue from the EC group (Fig. $3 J-L$ ), it can be seen that this group had many more labeled axons than the lesion (Fig. $3 A-C$ ), vehicle (Fig. $3 D-F$ ), or MP (Fig. $3 G-I$ ) groups. Although the number of labeled axons decreases in proportion to distance caudal to the injury (Fig. 4D), axons were visible even at the farthest distance analyzed (Fig. $3 L)$. In all tissue examined in the EC group, Cell Tracker greenlabeled ECs were found in the areas in which regrowing axons were located (Fig. 5). Analysis of the data demonstrated that, compared with the lesion, vehicle, and MP groups, the EC group had significantly more axons at all distances examined (Fig. 4). These data support the functional findings, which demonstrated that the rats receiving ECs regained significantly more CST function than the lesion, vehicle, and MP groups.

At $1 \mathrm{~mm}$ distal to the injury, the mean of the MP/EC group was not significantly different from the rats in the sham control group (Figs. $3 A, P, 4 A, D)$. After $1 \mathrm{~mm}$, the sham group had significantly more axons than the $\mathrm{MP} / \mathrm{EC}$ group (Figs. $3 M-R, 4$ ). As with the EC group, the number of labeled axons in the MP/EC group decreased as distance from the lesion increased (Fig. 3M-O, 4D), but axons could still be seen at $19 \mathrm{~mm}$ (Fig. 3O). As in the EC group, the $\mathrm{MP} / \mathrm{EC}$ group exhibited ECs that were visible throughout the regions in which axons were found (Fig. 5). Statistical analysis revealed that the MP/EC group had significantly more axons than the lesion, vehicle, and MP groups at all distances examined (Fig. 4), which agrees with the functional findings presented above. When the means from the group that received the combined treatment were compared with the means from the group that received only ECs, significant differences in results occurred at most distances caudal to the injury (Fig. 4). Analysis of the data from 1, 4, 7, 10, and $13 \mathrm{~mm}$ demonstrated 


\section{$1 \mathrm{~mm}$}

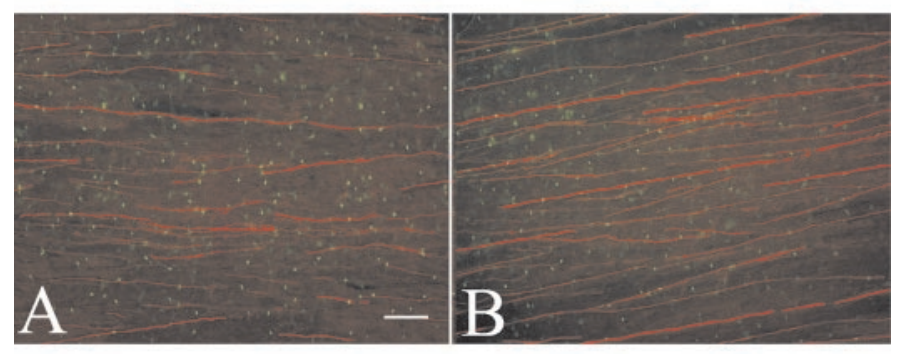

$7 \mathrm{~mm}$

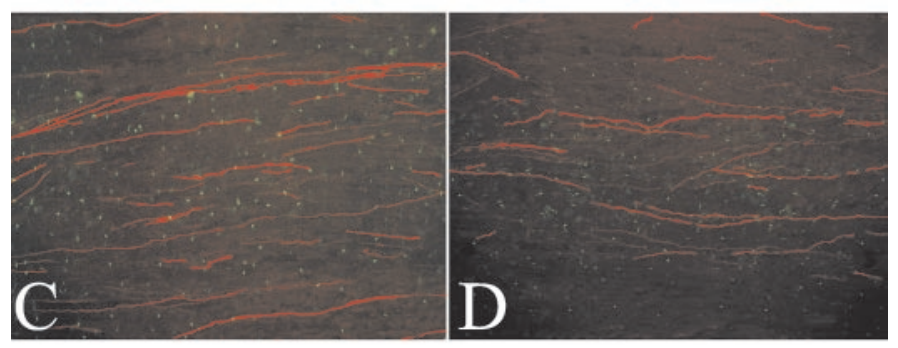

$13 \mathrm{~mm}$

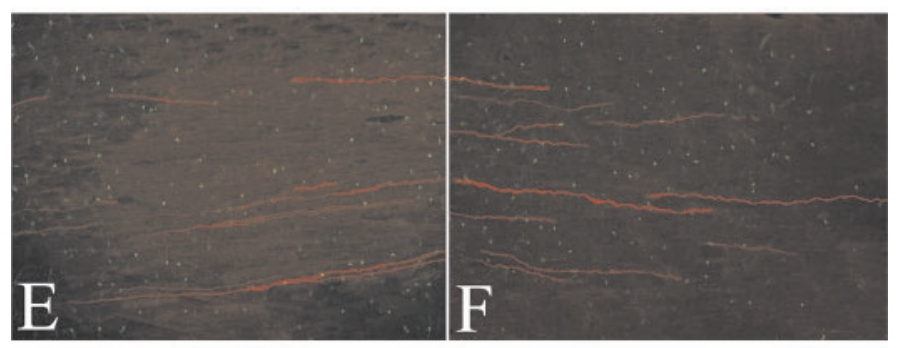

$19 \mathrm{~mm}$

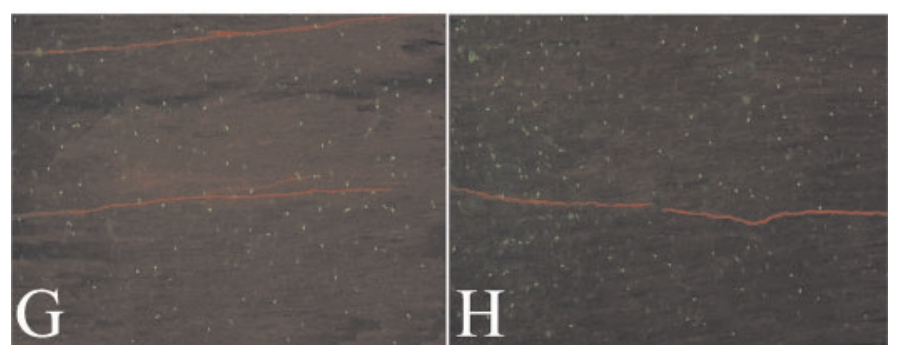

Figure 5. ECs colocalized with axons. Photomicrographs of BDTlabeled CST axons (red) surrounded by Cell Tracker green-labeled ECs. ECs in both the EC and MP/EC groups were at all distances, and representative images are shown from $1 \mathrm{~mm}$ ( $A$ and $B$, respectively), $7 \mathrm{~mm}$ $(C$ and $D), 13 \mathrm{~mm}(E$ and $F)$, and $19 \mathrm{~mm}(G$ and $H)$, the farthest distance analyzed. Scale bar, $50 \mu \mathrm{m}$.

that the $\mathrm{MP} / \mathrm{EC}$ group had significantly more axons than the EC group (Fig. $4 A, B, D$ ). However, no significant differences between the means of these two groups were found at 16 and $19 \mathrm{~mm}$ caudal to the lesion (Fig. 4C,D). This lack of significant differences between the means of the EC and MP/EC groups at the farthest distances analyzed may explain the lack of a significant difference between the DFR performance of these two groups but may have resulted in functional differences with a longer recovery period.

\section{DISCUSSION}

Currently, there is no treatment regimen available to restore sensory and motor function after debilitating SCI in humans. However, progress is being made in animal research. Numerous treatment strategies are being investigated to repair damaged axons after SCI in rats (David and Aguayo, 1981; Goldberg and Bernstein, 1987; Schnell and Schwab, 1993; Joosten et al., 1995; Xu et al., 1995; Chen et al., 1996; Kalderon and Fuks, 1996; Bregman et al., 1997; Guest et al., 1997; Oudega et al., 1997; Ye and Houle, 1997; Ramon-Cueto et al., 1998).

Among these strategies are the transplantation of various cell types, including fetal cells (Kunkel-Bagden and Bregman, 1990; Bernstein-Goral and Bregman, 1997; Mori et al., 1997; Bregman et al., 1998; Diener and Bregman, 1998a; McDonald, 1999) and Schwann cells (Kuhlengel et al., 1990; Li and Raisman, 1994; Xu et al., 1995; Chen et al., 1996; Martin et al., 1996; Guest et al., 1997). Fetal spinal cord transplants have been shown to support the regrowth of CST, raphespinal, and rubrospinal axons (Diener and Bregman, 1998b), as well as promote functional recovery after injuries to the neonatal spinal cord (Diener and Bregman, 1998a). The transplantation of murine embryonic stem cells into lesioned adult rat spinal cords has resulted in enhanced weight bearing and coordination of hindlimbs (McDonald, 1999). However, there are a number of ethical issues surrounding the use of embryonic tissues that must be resolved before its use in a clinical setting.

Schwann cells have also been shown to promote regeneration after SCI. Schwann cells have been found to be most effective when transplanted immediately after lesioning, resulting in reduced gliosis, improved Schwann cell survival, and improved regeneration of axons (Martin et al., 1996). Transplanted Schwann cells have been shown to induce axonal sprouting ( $\mathrm{Li}$ and Raisman, 1994), regrowth into the lesion (Xu et al., 1997), and, when used in combination with methylprednisolone, the regrowth of axons beyond the lesion into the host spinal cord and produce modest functional improvement (Guest et al., 1997). Although transplanted Schwann cells encourage axonal regrowth and improve function, Schwann cells do not thrive well in the CNS. A number have studies have shown that Schwann cells have a poor survivability rate in the presence of astrocytes, and their ability to remyelinate is diminished (Franklin and Blakemore, 1993; Iwaniuk et al., 1999). In an astrocyte-free environment, Schwann cell remyelination is much more prevalent (Duncan et al., 1988; Shields et al., 2000). This is because, although Schwann cells transplanted into the CNS are capable of promoting CNS axon regeneration, Schwann cells do not integrate well with astrocytes, a primary component of CNS lesion sites (Lakatos et al., 2000). The ideal candidate for CNS transplantation may be a cell type that endogenously exists in the CNS and is therefore able to thrive in the CNS environment, as well as promote regeneration and remyelination. A cell type that meets these criteria is the EC (Franklin and Barnett, 1997; Ramon-Cueto and Avila, 1998; Bartolomei and Greer, 2000; Lakatos et al., 2000), shown recently to promote regeneration after SCI.

Investigators have examined previously the ability of ECs to promote axonal regeneration after SCI (Li et al., 1997, 1998; Imaizumi et al., 2000; Ramon-Cueto et al., 2000; Lu et al., 2001). Our results support data that has been reported previously regarding the ability of ECs to promote axonal regeneration and functional recovery. As in our study, previous research by Li et al. (1998) and Ramon-Cueto et al. (2000) found the transplanted 
ECs promoted the regrowth of CST axons grown through the lesioned site. Transplanted ECs have also been reported previously to promote functional recovery (Li et al., 1997; RamonCueto et al., 2000), a finding that our data supports.

The ability of ECs to promote axonal regeneration when combined with other therapies has also been investigated (RamonCueto et al., 1998), but no one had investigated ECs in combination with MP. The combined effects of these two therapies are critical in determining whether ECs are to be considered for use in humans, because MP is the only current treatment used clinically after an acute SCI (Bracken et al., 1984, 1990, 1997).

In the experiments described herein, MP was found to promote axonal regeneration and improve functional recovery after SCI when compared with untreated rats. These improvements, although statistically significant, were not sufficient to result in complete restoration of DFR function (57\%), probably resulting from the limited distance that axons were found to regenerate $(\sim 7 \mathrm{~mm})$. In contrast, treatment with ECs resulted in axonal elongation to the farthest distance analyzed caudal to the injury site $(19 \mathrm{~mm})$ and the highest functional scores of all of the lesioned rats. This elongation was found whether ECs were applied alone or in combination with MP. Although more axons were found in the $\mathrm{MP} / \mathrm{EC}$ group than the EC group at distances up to $13 \mathrm{~mm}$ caudal to the lesion, this increase in axons was not enough to significantly improve DFR performance of the MP/EC group (78\%) when compared with the EC group (72\%). However, given more time, it is possible that the larger number of axons seen at shorter distances could extend farther, resulting in more functional recovery in the $\mathrm{MP} / \mathrm{EC}$ group.

It is equally critical to note is that, when MP was used in combination with ECs, there was not a decrease in axonal regeneration or functional recovery, which was a potential concern. Astrocytes have the capacity to act as immune cells (Dong and Benveniste, 2001), and MP is known to suppress the function of immune cells (Wahl et al., 1975; Almawi et al., 1991). Because ECs share phenotypic characteristics with astrocytes, it was possible that MP could have suppressed the function of ECs, resulting in a decreased effect in the MP/EC group. Investigation into the mechanisms of action of MP and ECs yield little insight because, as seen below, the mechanism of action for MP is still hotly debated and the mechanism of action for ECs is just starting to be elucidated.

One mechanism to explain the action of MP is through binding of the glucocorticoid receptor, which mediates its anti-inflammatory properties. MP inhibits inflammatory processes induced after SCI (Hsu and Dimitrijevic, 1990), such as chemotaxis (Espersen et al., 1989) and the release of lysosomal enzymes (Schleimer et al., 1989). MP also inhibits phospholipase A2 activity (Hirata et al., 1980), which reduces the production of metabolites of the arachidonic acid cascade (Becker and Grasso, 1985) thereby reducing the formation of free radicals (Hirata et al., 1980; Becker and Grasso, 1985; Kontos et al., 1985; Williams and Higgs, 1988). MP also reduces expression of tumor necrosis factor $\alpha$, decreasing the activation of nuclear factor- $\kappa \mathrm{B}$ (Xu et al., 1998), thereby diminishing the intensity and duration of the inflammatory response (Xu et al., 1998). Whereas these effects are achieved with administration of MP at a dose of $0.03 \mathrm{mg} / \mathrm{kg}$ (Young et al., 1988), to be clinically effective after SCI, MP must be administered at the large dose of $30 \mathrm{mg} / \mathrm{kg}$ (Hall et al., 1984). At this dose, MP exhibits antioxidant effects, which allows it to scavenge free radicals, thus decreasing the oxygen radical-induced lipid peroxidation of cell membranes (Demopoulos et al., 1980).
This mechanism is believed to be independent of the glucocorticoid receptor-mediated actions of MP, as evidenced by the large dose required to achieve these effects (Hall et al., 1984). Also supporting this theory are data demonstrating that synthetic steroids created to have greater antioxidant effects than MP, but lacking any glucocorticoid activity, are as effective as MP when applied after SCI (Hall, 1993).

The mechanism of action of ECs is still unknown, but clues about the mechanism of action are beginning to emerge. ECs were found to promote the growth of retinal ganglion neurites in coculture (Sonigra et al., 1999). Speculating that calciummediated signal transduction may be involved in the growthpromoting properties of ECs, the calcium channel inhibitors verapamil and $\omega$-conotoxin, as well as BAPTA-AM, a calcium chelator, were applied to the cocultures. Application of these inhibitors blocked the increase in axonal growth in the cocultures, leading to the conclusion that ECs may promote regeneration through calcium-signaling pathways (Sonigra et al., 1999). A subsequent study (Kafitz and Greer, 1999) demonstrated that olfactory receptor cell extension in culture was facilitated by exposure to media conditioned by ECs, indicating that the neurite growthpromoting properties of ECs were, at least in part, mediated by diffusible factors. Data supporting this idea was reported earlier this year, when cultured ECs were found to express nerve growth factor, brain-derived neurotrophic factor, and glial cell linederived neurotrophic factor (Woodhall et al., 2001).

Whereas these data provided two mechanisms of action for MP and insights into possible mechanisms for ECs, what they did not provide is any insight into the effects of using MP and ECs in combination. However, the study described in this paper does. These experiments demonstrated that ECs, not only alone but also in combination with $\mathrm{MP}$, are able to promote regrowth and extension of CST axons after trauma to the adult rat spinal cord. In fact, although no statistical difference was found between the EC and MP/EC groups functionally, a significant increase in axon numbers up to $13 \mathrm{~mm}$ caudal to the lesion indicate that MP may improve the regenerative properties of ECs.

Results using ECs to repair damaged spinal cord axons in animal studies have been so successful that researchers are now beginning to investigate the feasibility of transplanting ECs into human beings. Pig ECs had been genetically engineered to express a human complement inhibitory protein, which is intended to decrease rejection of the tissue if transplanted into human beings (Imaizumi et al., 2000). After transplantation into adult rats after dorsal column transection, pig EC transplants promoted axonal regeneration, elongation, and remyelination and restored impulse conduction across the lesion site (Imaizumi et al., 2000). Although rodent and porcine ECs promote repair after SCI, little has been determined about human ECs. Recently, ECs, obtained from adult human olfactory nerves removed from patients undergoing olfactory nerve resection, were transplanted into the demyelinated spinal cords of adult rats (Kato et al., 2000). Extensive remyelination, characteristic of ECs, was observed throughout the lesion site, demonstrating that human ECs are able to promote remyelination (Kato et al., 2000). These results further demonstrate that ECs have good potential for treating spinal cord injuries in human beings.

The experiments described herein confirm that ECs promote axonal regeneration and elongation, resulting in recovery of DFR behavior after SCI in adult rats. The morphological and functional regenerative properties of ECs were not hindered when used in combination with MP. Instead, the ability of ECs to 
promote axonal regeneration was enhanced as far as $13 \mathrm{~mm}$ caudal to the lesion. Demonstrating that ECs do not lose their regenerative properties when used in combination with MP provides another clinically relevant step toward solving the spinal cord injury problem.

\section{REFERENCES}

Almawi WY, Hadro ET, Strom TB (1991) Evidence that glucocorticosteroid-mediated immunosuppressive effects do not involve altering second messenger function. Transplantation 52:133-140.

Bartolomei JC, Greer CA (2000) Olfactory ensheathing cells: bridging the gap in spinal cord injury. Neurosurgery 47:1057-1069.

Becker J, Grasso RJ (1985) Suppression of phagocytosis by dexamethasone in macrophage cultures: inability of arachidonic acid, indomethacin, and nordihydroguaiaretic acid to reverse the inhibitory response mediated by a steroid-inducible factor. Int J Immunopharmacol 7:839-847.

Bernstein-Goral H, Bregman BS (1997) Axotomized rubrospinal neurons rescued by fetal spinal cord transplants maintain axon collaterals to rostral CNS targets. Exp Neurol 148:13-25.

Bracken MB, Collins WF, Freeman DF, Shepard MJ, Wagner FW, Silten RM, Hellenbrand KG, Ransohoff J, Hunt WE, Perot Jr PL, Grossman RG, Green BA, Eisenberg HM, Rifkinson N, Goodman JH, Meagher JN, Fischer B, Clifton GL, Flamm ES, Rawe SE (1984) Efficacy of methylprednisolone in acute spinal cord injury. JAMA 251:45-52.

Bracken MB, Shepard MJ, Collins WF, Holford TR, Young W, Baskin DS, Eisenberg HM, Flamm E, Leo-Summers L, Maroon J, Marshall LF, Perot Jr PL, Piepmier J, Sonntag UKH, Wagner FC, Wilberger JE, Winn HR (1990) A randomized, controlled trial of methylprednisolone or naloxone in the treatment of acute spinal-cord injury. Results of the Second National Acute Spinal Cord Injury Study. N Engl J Med 322:1405-1411.

Bracken MB, Shepard MJ, Holford TR, Leo-Summers L, Aldrich EF, Fazl M, Fehlings M, Herr DL, Hitchon PW, Marshall LF, Nockels RP, Pascale V, Perot Jr PL, Piepmeier J, Sonntag VK, Wagner F, Wilberger JE, Winn HR, Young W (1997) Administration of methylprednisolone for 24 or 48 hours or tirilazad mesylate for 48 hours in the treatment of acute spinal cord injury. Results of the Third National Acute Spinal Cord Injury Randomized Controlled Trial. National Acute Spinal Cord Injury Study. JAMA 277:1597-1604.

Braughler JM, Hall ED (1982) Pharmacokinetics of methylprednisolone in cat plasma and spinal cord following a single intravenous dose of the sodium succinate ester. Drug Metab Dispos 10:551-552.

Braughler JM, Hall ED (1983) Uptake and elimination of methylprednisolone from contused cat spinal cord following intravenous injection of the sodium succinate ester. J Neurosurg 58:538-542.

Braughler JM, Hall ED (1984) Effects of multi-dose methylprednisolone sodium succinate administration on injured cat spinal cord neurofilament degradation and energy metabolism. J Neurosurg 61:290-295.

Braughler JM, Hall ED, Means ED, Waters TR, Anderson DK (1987) Evaluation of an intensive methylprednisolone sodium succinate dosing regimen in experimental spinal cord injury. J Neurosurg 67:102-105.

Bregman BS, McAtee M, Dai HN, Kuhn PL (1997) Neurotrophic factors increase axonal growth after spinal cord injury and transplantation in the adult rat. Exp Neurol 148:475-494.

Bregman BS, Broude E, McAtee M, Kelley MS (1998) Transplants and neurotrophic factors prevent atrophy of mature CNS neurons after spinal cord injury. Exp Neurol 149:13-27.

Castro AJ (1972) The effects of cortical ablations on digital usage in the rat. Brain Res 37:173-185.

Castro AJ (1977) Limb preference after lesions of the cerebral hemisphere in adult and neonatal rats. Physiol Behav 18:605-608.

Chen A, Xu XM, Kleitman N, Bunge MB (1996) Methylprednisolone administration improves axonal regeneration into Schwann cell grafts in transected adult rat thoracic spinal cord. Exp Neurol 138:261-276.

David S, Aguayo AJ (1981) Axonal elongation into peripheral nervous system "bridges" after central nervous system injury in adult rats. Science 214:931-933.

Demopoulos HB, Flamm ES, Pietronigro DD, Seligman ML (1980) The free radical pathology and the microcirculation in the major central nervous system disorders. Acta Physiol Scand Suppl 492:91-119.

Diener PS, Bregman BS (1998a) Fetal spinal cord transplants support the development of target reaching and coordinated postural adjustments after neonatal cervical spinal cord injury. J Neurosci 18:763-778.

Diener PS, Bregman BS (1998b) Fetal spinal cord transplants support growth of supraspinal and segmental projections after cervical spinal cord hemisection in the neonatal rat. J Neurosci 18:779-793.

Dong Y, Benveniste EN (2001) Immune function of astrocytes. Glia 36:180-190.

Doucette R (1984) The glial cells in the nerve fiber layer of the rat olfactory bulb. Anat Rec 210:385-391.

Doucette R (1991) PNS-CNS transitional zone of the first cranial nerve. J Comp Neurol 312:451-466.
Doucette R (1993) Glial cells in the nerve fiber layer of the main olfactory bulb of embryonic and adult mammals. Microsc Res Tech 24:113-130.

Duncan ID, Hammang JP, Jackson KF, Wood PM, Bunge RP, Langford L (1988) Transplantation of oligodendrocytes and Schwann cells into the spinal cord of the myelin-deficient rat. J Neurocytol 17:351-360.

Espersen GT, Ernst E, Vestergaard M, Pedersen JO, Grunnet N (1989) Changes in PMN leukocyte migration activity and complement $\mathrm{C} 3 \mathrm{~d}$ levels in RA patients with high disease activity during steroid treatment. Scand J Rheumatol 18:51-56.

Fawcett JW, Keynes RJ (1990) Peripheral nerve regeneration. Annu Rev Neurosci 13:43-60.

Franklin RJ, Barnett SC (1997) Do olfactory glia have advantages over Schwann cells for CNS repair? J Neurosci Res 50:665-672.

Franklin RJ, Barnett SC (2000) Olfactory ensheathing cells and CNS regeneration: the sweet smell of success? Neuron 28:15-18.

Franklin RJ, Blakemore WF (1993) Requirements for Schwann cell migration within CNS environments: a viewpoint. Int J Dev Neurosci 11:641-649.

Goldberg WJ, Bernstein JJ (1987) Transplant-derived astrocytes migrate into host lumbar and cervical spinal cord after implantation of E14 fetal cerebral cortex into adult thoracic spinal cord. J Neurosci Res 17:391-403.

Graziadei PPC, Monti-Graziadei GA (1978) The olfactory system: a model for the study of neurogenesis and axon regeneration in mammals. In: Neuronal plasticity (Cotman CW, ed), pp 131-153. New York: Raven.

Guest JD, Rao A, Olson L, Bunge MB, Bunge RP (1997) The ability of human Schwann cell grafts to promote regeneration in the transected nude rat spinal cord. Exp Neurol 148:502-522.

Hall ED (1992) The neuroprotective pharmacology of methylprednisolone. J Neurosurg 76:13-22.

Hall ED (1993) Neuroprotective actions of glucocorticoid and nonglucocorticoid steroids in acute neuronal injury. Cell Mol Neurobiol 13:415-432.

Hall ED, Wolf DL, Braughler JM (1984) Effects of a single large dose of methylprednisolone sodium succinate on experimental postraumatic spinal cord ischemia. Dose-response and time-action analysis. J Neurosurg 61:124-130.

Hirata F, Schiffmann E, Venkatasubramanian K, Salomon D, Axelrod J (1980) A phospholipase A2 inhibitory protein in rabbit neutrophils induced by glucocorticoids. Proc Natl Acad Sci USA 77:2533-2536.

Hsu CY, Dimitrijevic MR (1990) Methylprednisolone in spinal cord injury: the possible mechanism of action. J Neurotrauma 7:115-119.

Imaizumi T, Lankford KL, Burton WV, Fodor WL, Kocsis JD (2000) Xenotransplantation of transgenic pig olfactory ensheathing cells promotes axonal regeneration in rat spinal cord. Nat Biotechnol 18:949-953.

Iwaniuk AN, Pellis SM, Whishaw IQ (1999) Is digital dexterity really related to corticospinal projections?: a re-analysis of the Heffner and Masterton data set using modern comparative statistics. Behav Brain Res 101:173-187.

Joosten EA, Bar PR, Gispen WH (1995) Collagen implants and corticospinal axonal growth after mid-thoracic spinal cord lesion in the adult rat. J Neurosci Res 41:481-490.

Kafitz KW, Greer CA (1999) Olfactory ensheathing cells promote neurite extension from embryonic olfactory receptor cells in vitro. Glia 25:99-110.

Kalderon N, Fuks Z (1996) Severed corticospinal axons recover electrophysiologic control of muscle activity after x-ray therapy in lesioned adult spinal cord. Proc Natl Acad Sci USA 93:11185-11190.

Kartje-Tillotson G, Castro AJ (1980) Limb preference after unilateral pyramidotomy in adult and neonatal rats. Physiol Behav 24:293-296.

Kato T, Honmou O, Uede T, Hashi K, Kocsis JD (2000) Transplantation of human olfactory ensheathing cells elicits remyelination of demyelinated rat spinal cord. Glia 30:209-218.

Kontos HA, Wei EP, Ellis EF, Jenkins LW, Povlishock JT, Rowe GT, Hess ML (1985) Appearance of superoxide anion radical in cerebra extracellular space during increased prostaglandin synthesis in cats. Circ Res 57:142-151.

Kosaka K, Toida K, Aika Y, Kosaka T (1998) How simple is the organization of the olfactory glomerulus?: the heterogeneity of so-called periglomerular cells. Neurosci Res 30:101-110.

Kuhlengel KR, Bunge MB, Bunge RP, Burton H (1990) Implantation of cultured sensory neurons and Schwann cells into lesioned neonatal rat spinal cord. II. Implant characteristics and examination of corticospinal tract growth. J Comp Neurol 293:74-91.

Kunkel-Bagden E, Bregman BS (1990) Spinal cord transplants enhance the recovery of locomotor function after spinal cord injury at birth. Exp Brain Res 81:25-34.

Lakatos A, Franklin RJ, Barnett SC (2000) Olfactory ensheathing cells and Schwann cells differ in their in vitro interactions with astrocytes. Glia 32:214-225.

Li Y, Raisman G (1994) Schwann cells induce sprouting in motor and sensory axons in the adult rat spinal cord. J Neurosci 14:4050-4063. 
Li Y, Field PM, Raisman G (1997) Repair of adult rat corticospinal tract by transplants of olfactory ensheathing cells. Science 277:2000-2002.

Li Y, Field PM, Raisman G (1998) Regeneration of adult rat corticospinal axons induced by transplanted olfactory ensheathing cells. J Neurosci 18:10514-10524.

Lu J, Feron F, Ho SM, Mackay-Sim A, Waite PM (2001) Transplantation of nasal olfactory tissue promotes partial recovery in paraplegic adult rats. Brain Res 889:344-357.

Martin D, Robe P, Franzen R, Delree P, Schoenen J, Stevenaert A, Moonen G (1996) Effects of Schwann cell transplantation in a contusion model of rat spinal cord injury. J Neurosci Res 45:588-597.

McDonald JW (1999) Transplanted embryonic stem cells survive, differentiate and promote recovery in injured rat spinal cord. Nat Med 5:1410-1412

McGinley PA, Braughler JM, Hall ED (1982) Determination of methylprednisolone in central nervous tissue and plasma using normal-phase high-performance liquid chromatography. J Chromatogr 230:29-35.

Mori F, Himes BT, Kowada M, Murray M, Tessler A (1997) Fetal spinal cord transplants rescue some axotomized rubrospinal neurons from retrograde cell death in adult rats. Exp Neurol 143:45-60.

Nash HH, Borke RC, Anders JJ (2001) New method of purification for establishing primary cultures of ensheathing cells from the adult olfactory bulb. Glia 34:81-87.

Nicholls JG, Adams WB, Eugenin J, Geiser R, Lepre M, Luque JM, Wintzer M (1999) Why does the central nervous system not regenerate after injury? Surv Ophthalmol 43:S136-S141.

Oudega M, Xu XM, Guenard V, Kleitman N, Bunge MB (1997) A combination of insulin-like growth factor-I and platelet-derived growth factor enhances myelination but diminishes axonal regeneration into Schwann cell grafts in the adult rat spinal cord. Glia 19:247-258.

Raisman G (2001) Olfactory ensheathing cells-another miracle cure for spinal cord injury? Nat Rev Neurosci 2:369-375.

Raivich G, Kreutzberg GW (1993) Peripheral nerve regeneration: role of growth factors and their receptors. Int J Dev Neurosci 11:311-324.

Ramon-Cueto A, Avila J (1998) Olfactory ensheathing glia: properties and function. Brain Res Bull 46:175-187.

Ramon-Cueto A, Nieto-Sampedro M (1994) Regeneration into the spinal cord of transected dorsal root axons is promoted by ensheathing glia transplants. Exp Neurol 127:232-244.

Ramon-Cueto A, Plant GW, Avila J, Bunge MB (1998) Long-distance axonal regeneration in the transected adult rat spinal cord is promoted by olfactory ensheathing glia transplants. J Neurosci 18:3803-3815.

Ramon-Cueto A, Cordero MI, Santos-Benito FF, Avila J (2000) Func- tional recovery of paraplegic rats and motor axon regeneration in their spinal cords by olfactory ensheathing glia. Neuron 25:425-435.

Schleimer RP, Freeland HS, Peters SP, Brown KE, Derse CP (1989) An assessment of the effects of glucocorticoids on degranulation, chemotaxis, binding to vascular endothelium and formation of leukotriene B4 by purified human neutrophils. J Pharmacol Exp Ther 250:598-605.

Schnell L, Schwab ME (1993) Sprouting and regeneration of lesioned corticospinal tract fibres in the adult rat spinal cord. Eur J Neurosci 5:1156-1171.

Schwab ME, Bartholdi D (1996) Degeneration and regeneration of axons in the lesioned spinal cord. Physiol Rev 76:319-370.

Shields SA, Blakemore WF, Franklin RJ (2000) Schwann cell remyelination is restricted to astrocyte-deficient areas after transplantation into demyelinated adult rat brain. J Neurosci Res 60:571-578.

Sonigra RJ, Brighton PC, Jacoby J, Hall S, Wigley CB (1999) Adult rat olfactory nerve ensheathing cells are effective promoters of adult central nervous system neurite outgrowth in coculture. Glia 25:256-269.

Treloar HB, Bartolomei JC, Lipscomb BW, Greer CA (2001) Mechanisms of axonal plasticity: lessons from the olfactory pathway. The Neuroscientist 7:55-63.

Wahl SM, Altman LC, Rosenstreich DL (1975) Inhibition of in vitro lymphokine synthesis by glucocorticosteroids. J Immunol 115:476-481.

Williams KI, Higgs GA (1988) Eicosanoids and inflammation. J Pathol 156:101-110.

Woodhall E, West AK, Chuah MI (2001) Cultured olfactory ensheathing cells express nerve growth factor, brain-derived neurotrophic factor, glia cell line-derived neurotrophic factor and their receptors. Brain Res Mol Brain Res 88:203-213.

Xu J, Fan G, Chen S, Wu Y, Xu XM, Hsu CY (1998) Methylprednisolone inhibition of TNF-alpha expression and NF-kB activation after spinal cord injury in rats. Brain Res Mol Brain Res 59:135-142.

Xu XM, Guenard V, Kleitman N, Bunge MB (1995) Axonal regeneration into Schwann cell-seeded guidance channels grafted into transected adult rat spinal cord. J Comp Neurol 351:145-160.

Xu XM, Chen A, Guenard V, Kleitman N, Bunge MB (1997) Bridging Schwann cell transplants promote axonal regeneration from both the rostral and caudal stumps of transected adult rat spinal cord. J Neurocytol 26:1-16.

Ye JH, Houle JD (1997) Treatment of the chronically injured spinal cord with neurotrophic factors can promote axonal regeneration from supraspinal neurons. Exp Neurol 143:70-81.

Young W, DeCrescito V, Flamm ES, Blight AR, Gruner JA (1988) Pharmacological therapy of acute spinal cord injury: studies of high dose methylprednisolone and naloxone. Clin Neurosurg 34:675-697. 